\title{
Transformation of para arsanilic acid by manganese oxide: Adsorption, oxidation, and influencing factors
}

 \\ Jiuhui $Q u^{\text {a, } c}$ \\ ${ }^{a}$ Key Laboratory of Drinking Water Science and Technology, Research Center for Eco-Environmental Sciences, Chinese Academy of Sciences, Beijing 100085, \\ China \\ b State Key Laboratory of Environmental Aquatic Chemistry, Research Center for Eco-Environmental Sciences, Chinese Academy of Sciences, Beijing 100085, \\ China \\ ${ }^{\mathrm{c}}$ University of Chinese Academy of Sciences, Beijing 100049, China
}

\section{A $\quad R \quad T$ I C L L E I I N F}

\section{Article history:}

Received 19 December 2016

Received in revised form

8 March 2017

Accepted 11 March 2017

Available online 18 March 2017

\section{Keywords:}

Para arsanilic acid

Phenylarsonic acid

Aniline

Arsenate

Benzoquinone

Azophenylarsonic acid

\begin{abstract}
A B S T R A C $T$
Aromatic organoarsenic compounds tend to transform into more mobile toxic inorganic arsenic via several processes, and can inadvertently spread toxic inorganic arsenic through the environment to water sources. To gain insight into the transformation mechanisms, we herein investigated how the process of para arsanilic acid ( $p$-ASA) transformation works in detail on the surface of adsorbents by comparing it with phenylarsonic acid (PA) and aniline, which have similar chemical structures. In contrast to the values of $0.23 \mathrm{mmol} \mathrm{g}^{-1}$ and $0.68 \mathrm{mmol} \mathrm{g}^{-1}$ for PA and aniline, the maximum adsorption capacity was determined to be $0.40 \mathrm{mmol} \mathrm{g}^{-1}$ for $p$-ASA at $\mathrm{pH} 4.0$. The results of FTIR and XPS spectra supported the presence of a protonated amine, resulting in a suitable condition for the oxidation of $p$ ASA. Based on the combined results of UV-spectra and UPLC-Q-TOF-MS, we confirmed that the adsorbed p-ASA was first oxidized through the transfer of one electron from $p$-ASA on $\mathrm{MnO}_{2}$ surface to form a radical intermediate, which through further hydrolysis and coupling led to formation of benzoquinone and azophenylarsonic acid, which was identified as a major intermediate. After that, $p$-ASA radical intermediate was cleaved to form arsenite (III), and then further oxidized into arsenate (V) with the release of manganese $(\mathrm{Mn})$ into solution, indicating a heterogeneous oxidation process.
\end{abstract}

(C) 2017 Published by Elsevier Ltd.

\section{Introduction}

The aromatic organoarsenic compounds such as para-arsanilic acid ( $p$-ASA) have been extensively applied as feed additives for poultry to treat coccidial intestinal parasites, enhance feed efficiency, promote rapid growth, and to improve meat pigmentation (Chapman and Johnson, 2002; Garbarino et al., 2003). Most of the organoarsenic compounds are excreted chemically unchanged in the manure (Morrison, 1969), which is widely used in agricultural applications, then enter the environment through the poultry litter (Garbarino et al., 2003). Furthermore, it has been reported that the abiotic and biotic transformation of aromatic organoarsenic under

\footnotetext{
* Corresponding author. Key Laboratory of Drinking Water Science and Technology, Research Center for Eco-Environmental Sciences, Chinese Academy of Sciences, Beijing 100085, China.

E-mail address: liuruiping@rcees.ac.cn (R. Liu).
}

anaerobic conditions contributes to the release of more toxic inorganic arsenic (Cortinas et al., 2006; Stolz et al., 2007). p-ASA is highly mobile, and during the transformation process inorganic arsenic makes its way through the environment into surface and ground water sources (Depalma et al., 2008; Rutherford et al., 2003). Arsenic can also be absorbed by vegetables from soil and enter the food web, and ultimately transferred to human beings (Huang et al., 2014). For these reasons, it is crucial to remove aromatic organoarsenic compounds from the poultry manure to control organoarsenic transformation and entry into the environment.

A variety of removal techniques have been recently investigated to remove p-ASA, such as oxidation (Wang and Cheng, 2015), adsorption (Joshi et al., 2017; Jung et al., 2015), photo-catalytic degradation (Czaplicka et al., 2014; Zhu et al., 2014), and the Fenton process (Xie et al., 2016b). The main intermediates of the reaction have been identified as arsenite (III), arsenate (V), azophenylarsonic acid, benzoquinone, p-nitrophenol, aminophenol, aniline, nitrobenzene, phenol, hydroquinone, and ammonia 
$\left(\mathrm{NH}_{3}\right)$ (Table S1) (Mitchell et al., 2011; Wang and Cheng, 2015; Xie et al., 2016a, b; Zhu et al., 2014). However, the above studies did not examine the structural level adsorption mechanism, and it is hitherto unknown which functional group of $p$-ASA is most easily attacked. Herein, we describe our investigations on the behavior of the individual compounds PA and aniline, the analysis of which could provide in-depth mechanistic understanding of $p$-ASA transformation pathways. Structurally, $p$-ASA is a type of phenylarsonic acid molecule with substituted functional groups, where an amine group is added to phenylarsonic acid (PA) molecules at the para position to form para-arsanilic acid (p-ASA) (Mangalgiri et al., 2015). Aniline is part of an important family of industrial chemicals applied in the synthesis of several synthetic organic compounds such as pesticides, dyestuffs, pharmaceuticals products, and so on (Laha and Luthy, 1990; Weber et al., 1996). One of the methods for the preparation of $p$-ASA involves aniline as a starting material, which is reacted with arsenic at $392^{\circ} \mathrm{F}$ as shown in the following Eq. (1) (Ewies, 2013).

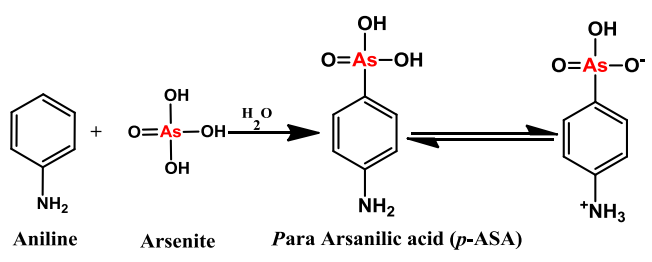

Manganese oxide $\left(\mathrm{MnO}_{2}\right)$ is generally applied to remove the toxic compounds in the environment because of its strong oxidizing property and has adsorptive capability (Cui et al., 2014; Manning et al., 2002). $\mathrm{MnO}_{2}$ is applied to remove $\mathrm{As}(\mathrm{III})$ through its oxidation to the more readily adsorbed $\mathrm{As}(\mathrm{V})$ species (Lafferty et al., 2010, 2011; Manning et al., 2002). Additionally, $\mathrm{MnO}_{2}$ could remove several organic pollutants including aromatic organoarsenic compound (Wang and Cheng, 2015), aromatic amines (Li et al., 2003), aniline (Klausen et al., 1997; Laha and Luthy, 1990), phenol (Stone, 1987), antibacterial agents (Chen et al., 2011; Gao et al., 2012; Zhang and Huang, 2005), and endocrine disrupters (Kunde et al., 2009).

The objectives of this study were to investigate the adsorptive and oxidative behavior of $\mathrm{MnO}_{2}$ for the removal of $p$-ASA under different $\mathrm{pH}$ conditions. Combining the results of inductively coupled plasma optical emission spectroscopy (ICP-OES), high performance liquid chromatography (HPLC), ultra-high performance liquid chromatography inductively coupled plasma mass spectroscopy (UPLC-ICP-MS), ultra-performance liquid chromatography-quadrupole-time-of-flight-mass spectrometry (UPLC-QTOF-MS), and UV-vis spectra, benzoquinone, azophenylarsonic acid, and inorganic arsenic species were confirmed as the main intermediates. Furthermore, Fourier transform infrared (FTIR) spectra and X-ray photoelectron spectroscopy (XPS) were employed in order to identify the adsorption products on $\mathrm{MnO}_{2}$ surface. We confirmed the formation of new oxidation products and recognized the major functional group of protonated amine, which was a crucial species in the transformation pathway.

\section{Materials and methods}

\subsection{Chemicals}

High purity $p$-ASA (TCI chemicals, China), PA (Strem Chemicals), and aniline (Beijing Chemical Co) were applied in this study. All solutions were prepared using analytical grade reagents. A stock solution containing $15 \mathrm{mmol} \mathrm{L}^{-1}$ of $p$-ASA, PA, and aniline was prepared in Milli-Q water (Millipore, 18.2 $\mathrm{M} \Omega \mathrm{cm}$ resistivity) and kept in the dark to avoid oxidation. Physicochemical properties and chemical structures of $p$-ASA, PA, and aniline are listed in Table S2. The ionic strength was established by adding $0.01 \mathrm{M} \mathrm{NaClO}_{4} \cdot \mathrm{H}_{2} \mathrm{O}$ as the background electrolyte. Details of the synthetic procedure for $\mathrm{MnO}_{2}$ and structural characterization methods such as specific surface area $\left(S_{B E T}\right)$, X-ray diffraction (XRD), Zeta ( $\left.\zeta_{-}\right)$potential, and scanning electron microscopy (SEM) and their results are provided in the supporting information (Text SI1, SI2, and SI5 and Figs. S1-S2).

\subsection{Experimental setup}

The initial concentration of $p$-ASA, PA, and aniline was $0.15 \mathrm{mmol} \mathrm{L}^{-1}$ and $\mathrm{MnO}_{2}$ dosage was $0.2 \mathrm{~g} \mathrm{~L}^{-1}$. Adsorption kinetic experiments were conducted in triplicate at the same time in

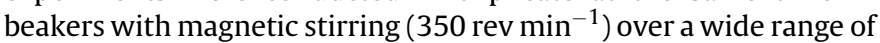
$\mathrm{pH}$ (4.0-9.0). The $\mathrm{pH}$ of the solution was measured at 3-4.0 h time intervals and adjusted to the desired value by drop-wise addition of $0.1 \mathrm{M} \mathrm{NaOH}$ and $0.1 \mathrm{M} \mathrm{HNO}_{3}$. Aliquots $(\sim 5 \mathrm{~mL})$ were taken from the suspension at different time periods of $0.066,0.1,0.33,0.48,0.6,1.0$, 1.5, 2.0, 3.0, 5.0, 6.0, 7.0, 9.0, 14.0, 23.0, and $24.0 \mathrm{~h}$. The adsorption performance ( $q t, \mathrm{mmol} \mathrm{g}^{-1}$ ) and removal rate of $\mathrm{MnO}_{2}$ towards $p$ ASA, PA, and aniline were calculated (Text SI-4).

\subsection{Analytical methods}

After adsorption, samples were filtered through a $0.45-\mu \mathrm{m}$ membrane, and arsenic (As) species and manganese ( $\mathrm{Mn}$ ) were analyzed via ICP-OES (ICP-OES-710 Agilent Technology, USA). UV-Visible absorption spectra were recorded with a UV-Vis spectrophotometer (U-3010 Hitachi High Technologies Co., Japan). The degradation products were identified by a Waters UPLC/DAD system equipped with a Q-TOF-MS (Massachusetts, USA). To identify the degradation products of $p$-ASA on $\mathrm{MnO}_{2}$ at $\mathrm{pH} 4.0,0.5 \mathrm{~mL}$ samples were dissolved in $0.25 \mathrm{M}$ of ascorbic acid and diluted with $4.5 \mathrm{~mL}$ of Milli-Q water. Separation was achieved by an Agilent C18 column $(2.1 \times 50 \mathrm{~mm}, 1.7-\mu \mathrm{m})$ at the flow rate of $0.2 \mathrm{~mL} \mathrm{~min}^{-1}$. An isocratic mobile phase consisting of $0.1 \%$ formic acid and pure methanol $(90: 10, v / v)$ was used for analysis of $p$-ASA and their products. The oxidation intermediates of $p$-ASA on $\mathrm{MnO}_{2}$ were measured over a wide range of $\mathrm{pH}$ by UPLC-ICP-MS (Thermo Scientific-iCAP-Q). The mobile phase solution was prepared by dissolving $10 \mathrm{mmol} \mathrm{L}^{-1}$ of $\left(\mathrm{NH}_{4}\right)_{2} \mathrm{HPO}_{4}$ and $10 \mathrm{mmol} \mathrm{L}^{-1}$ of $\mathrm{NH}_{4} \mathrm{NO}_{3}$ into $1 \mathrm{~L}$ of Milli-Q water. The $\mathrm{pH}$ was adjusted to 6.2 by adding $1 \mathrm{M}$ $\mathrm{HNO}_{3}$, which was ultra sonicated for $1.0 \mathrm{~h}$. It was passed through the column at $1.0 \mathrm{~mL} \mathrm{~min}^{-1}$ and $20-\mu \mathrm{L}$ samples were injected for the measurement. The mass spectrum (MS) detector was used to detect the peak of arsenic species at $m / z 75$ through the "time resolved analysis" mode (Zhang et al., 2015). The concentrations of arsenic species were calculated based on the peak areas and calibration curves established with the respective standard.

Similarly, the reactions of $p$-ASA and aniline with $\mathrm{MnO}_{2}$ over a wide range of $\mathrm{pH}$ (4.0-9.0) were measured using HPLC, Agilent Technology 1260 Infinity. The flow rate was maintained at $1.0 \mathrm{~mL} \mathrm{~min}^{-1}$ with a C18 column $(250 \times 4.6 \mathrm{~mm}, 5-\mu \mathrm{m})$ and a diode array UV-vis detector $260 \mathrm{~nm}$. The injection volume was $10-\mu \mathrm{L}$. Solvent A 80\% containing $\mathrm{KH}_{2} \mathrm{PO}_{4} 50 \mathrm{mmol} \mathrm{L}^{-1}$ and $\mathrm{HCOOH}(0.1 \%)$ and $\mathrm{B} 20 \%\left(\mathrm{CH}_{3} \mathrm{OH}\right)$ were used as a mobile phase. Each mobile phase was sonicated for $15 \mathrm{~min}$ to remove bubbles. Prepare four working standard solutions of $p$-ASA for the calibration with 4.0, 6.0, 8.0, and $10 \mathrm{mg} \mathrm{L}^{-1}$ concentrations. The adsorption kinetics of aniline onto $\mathrm{MnO}_{2}$ samples were filtered by $0.45 \mu \mathrm{m}$ membrane and analyzed in high performance liquid chromatography (HPLC, Agilent Technology 1260 infinity). The flow rate was maintained at $1.0 \mathrm{~mL} \mathrm{~min}{ }^{-1}$ 
with a C18 column $(250 \times 4.6 \mathrm{~mm}, 5-\mu \mathrm{m})$ and a diode array UV-vis detector $230 \mathrm{~nm}$. The injection volume was $40-\mu \mathrm{L}$ and the retention time was $10 \mathrm{~min}$. The mobile phase A consisted of $50 \%$ pure acetonitrile, while mobile phase B was $50 \%$ Milli-Q water (Laha and Luthy, 1990). Standard solution of aniline was prepared in different concentration range. Samples of the adsorbent were examined before and after adsorption by FTIR spectroscopy (Tensor 27 Bruker, Germany) and XPS was conducted using an ESCA-Lab-220i-XL spectrometer (Shimadzu, Japan) with monochromatic Al Ka radiation $(225 \mathrm{~W}, 15 \mathrm{~mA}, 15 \mathrm{kV})$ and the binding energy were calibrated with internal standard by use of the $\mathrm{C} 1 \mathrm{~s}$ peak at $284.80 \mathrm{eV}$ (Text SI3).

\section{Results and discussion}

\subsection{Adsorption kinetics}

Fig. 1 illustrates the adsorption kinetics of $p$-ASA, PA, and aniline onto $\mathrm{MnO}_{2}$ under different $\mathrm{pH}$ conditions (4.0-9.0) over $24.0 \mathrm{~h}$. Initially, the adsorption was rapid with a removal rate of $41.9 \%$, $14.7 \%$, and $95.0 \%$ for $p$-ASA, PA, and aniline respectively within $1.0 \mathrm{~h}$ of reaction time at $\mathrm{pH} 4.0$. However, it slowed down considerably later on, with only $14.2 \%$ of $p$-ASA, $22.1 \%$ of PA, and $4.1 \%$ of aniline removed in the rest of the $24.0 \mathrm{~h}$ reaction time (Fig. S3). Moreover,

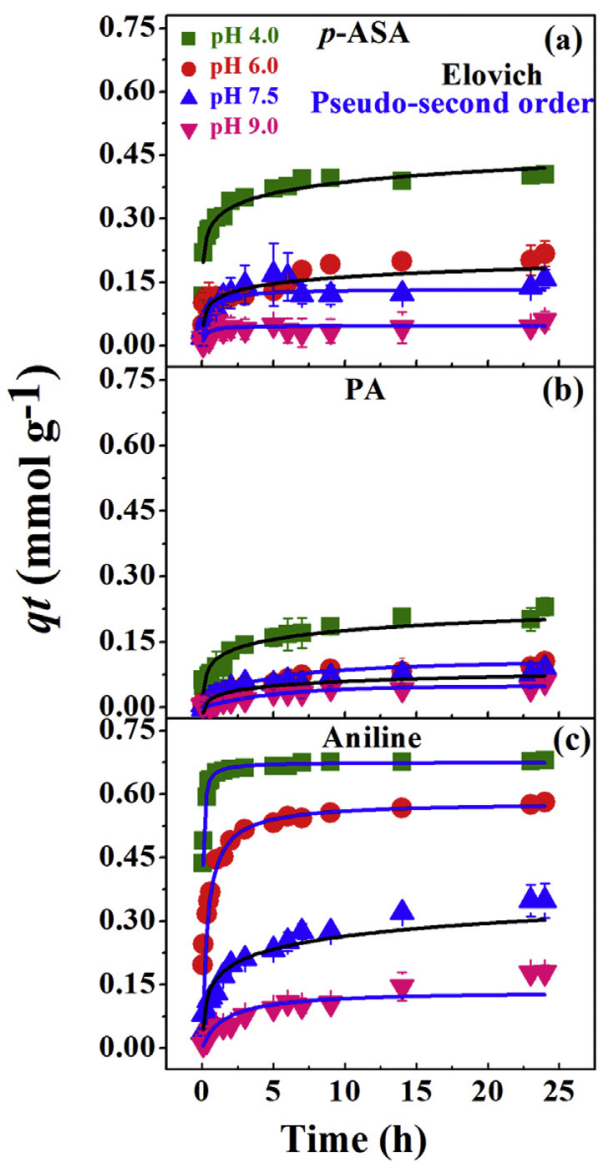

Fig. 1. Adsorption kinetics of (a) p-ASA, (b) $\mathrm{PA}$, and (c) aniline onto $\mathrm{MnO}_{2}$ over a wide range of $\mathrm{pH}$. The lines through the data points indicates the fitting by kinetics models, black line represent Elovich model and blue line denotes Pseudo-second order model. Experimental condition: $[p-A S A]_{0}=[\mathrm{PA}]_{0}=[\text { Aniline }]_{0}=0.15 \mathrm{mmol} \mathrm{L}^{-1}, \mathrm{pH}=4.0-9.0$, ionic strength $=0.01 \mathrm{M} \mathrm{NaClO}_{4} \cdot \mathrm{H}_{2} \mathrm{O}$, adsorbent doses $=0.2 \mathrm{~g} \mathrm{~L}^{-1}, T=25 \pm 1{ }^{\circ} \mathrm{C}$, $t=24.0 \mathrm{~h}$. (For interpretation of the references to colour in this figure legend, the reader is referred to the web version of this article.) adsorption equilibrium was achieved in $7.0 \mathrm{~h}$ for $p$-ASA, $14.0 \mathrm{~h}$ for $\mathrm{PA}$, and $1.0 \mathrm{~h}$ for aniline, indicating that the adsorption of aniline on $\mathrm{MnO}_{2}$ was faster than $p$-ASA and PA. Comparatively, the maximum equilibrium adsorption capacities $\left(q_{e q}\right)$ of $p$-ASA, PA, and aniline were found to be $0.40 \mathrm{mmol} \mathrm{g}^{-1}, 0.23 \mathrm{mmol} \mathrm{g}^{-1}$, and $0.68 \mathrm{mmol} \mathrm{g}^{-1}$ at $\mathrm{pH}$ 4.0. The removal rates of $p$-ASA, PA, and aniline by adsorption were strongly $\mathrm{pH}$ dependent, so that only $8.2 \%$ of $p$-ASA, $13.6 \%$ of PA, and $26.5 \%$ of aniline was adsorbed after $24.0 \mathrm{~h}$ contact time at $\mathrm{pH}$ 9.0 , indicating that the adsorption performance decreases when the $\mathrm{pH}$ increases from 4.0 to 9.0 (Fig. S4).

To understand the adsorption kinetics behavior, various models such as pseudo-first-order, pseudo-second-order, and Elovich models were fitted to the kinetics data (Table S3). The higher correlation coefficient $R^{2}$ at $\mathrm{pH} 4.0$ showed that $p$-ASA and PA were well fitted by the Elovich model, indicating the occurrence of heterosphere diffusion reactions (Mclintock, 1967). Furthermore, aniline was best fitted by the pseudo-second-order model, which suggested that the adsorption process might be chemisorption (Ho and Mckay, 1998). Comparison of these theoretical data agreed well with the experimental values obtained from the adsorption kinetics of $p$-ASA, PA, and aniline on $\mathrm{MnO}_{2}$ over a wide range of $\mathrm{pH}$.

Experimental data showed that $\mathrm{pH}$ played an influential role in the adsorption of $p$-ASA, PA, and aniline on $\mathrm{MnO}_{2}$, following the order pH $4.0>$ pH $6.0>$ pH $7.5>$ pH 9.0 (Fig. S4). First, the favorable adsorption/oxidation process in the lower $\mathrm{pH}$ condition was due to the fact that different environmental factors influence the extent and kinetics of $\mathrm{MnO}_{2}$ oxidation of organic pollutants, with $\mathrm{pH}$ playing a major role (Gao et al., 2012; Klausen et al., 1997; Wang and Cheng, 2015; Zhang and Huang, 2003, 2005). Second, the point of zero charge ( $p z c$ ) of $\mathrm{MnO}_{2}$ was about 2.0, so that there would be greater Coulombic repulsive electrostatic forces (Jung et al., 2015) with increasing $\mathrm{pH}$, leading to a decrease in removal. The data strongly suggested that protonated compounds on the positively charged surface of $\mathrm{MnO}_{2}$ at low $\mathrm{pH}$ reacted more strongly than the deprotonated forms on $\mathrm{MnO}_{2}$ with a negative surface charge (Zhang and Huang, 2005).

Release of Manganese $(\mathrm{Mn})$ resulting from the oxidation was also observed after the adsorption of $p$-ASA, PA, and aniline on $\mathrm{MnO}_{2}$ over a wide range of $\mathrm{pH}$ from 4.0 to 9.0 (Fig. 2). In agreement with the above oxidation results, $M n$ concentration was $17.5 \mathrm{mg} \mathrm{L}^{-1}, 9.8 \mathrm{mg} \mathrm{L}^{-1}$, and $1.2 \mathrm{mg} \mathrm{L}^{-1}$ for aniline, $p$-ASA, and PA respectively at $\mathrm{pH} 4.0$, and was found to be higher in the case of aniline. The concentration of $\mathrm{Mn}$ became lower with increasing $\mathrm{pH}$, $0.51 \mathrm{mg} \mathrm{L}^{-1}$ and $0.38 \mathrm{mg} \mathrm{L}^{-1}$ for $p$-ASA and aniline at $\mathrm{pH} 9.0$. However, the released Mn concentration was $5.5 \mathrm{mg} \mathrm{L}^{-1}$ for PA at $\mathrm{pH}$ 9.0. $\mathrm{Mn}$ was released into the solution as a result of $\mathrm{MnO}_{2}$ reduction through the oxidation of $p$-ASA and aniline (Gao et al., 2012; Laha and Luthy, 1990; Wang and Cheng, 2015).

\subsection{Oxidative behaviors and identification of intermediates}

Fig. 3 illustrates the changes in the UV spectra during the adsorption of $p$-ASA, $\mathrm{PA}$, and aniline onto $\mathrm{MnO}_{2}$ over a wide $\mathrm{pH}$ range (4.0-9.0). The shapes of UV-visible spectra varied with $\mathrm{pH}$ after the reaction of $p$-ASA, PA, and aniline with $\mathrm{MnO}_{2}$, indicating the occurrence of structural change from the formation of new products due to the oxidation of $p$-ASA and aniline. The absorbance band of $p$-ASA was at $254 \mathrm{~nm}$, which was attributed the presence of the aromatic ring (Zhu et al., 2014). After the reaction of $p$-ASA with $\mathrm{MnO}_{2}$ at $\mathrm{pH} 4.0$, the absorbance band at $254 \mathrm{~nm}$ decreased and shifted to $245 \mathrm{~nm}$ over the course of the reaction, indicating the presence of benzoquinone (Fig. 3a and Fig. S5a) (Clarke et al., 2013; Wang and Cheng, 2015). A new broad absorption band appeared in the range $310 \mathrm{~nm}-450 \mathrm{~nm}$ after $1.0 \mathrm{~h}$, and the intensity increased 




Fig. 2. Release of Manganese (Mn) after the adsorption of (a) p-ASA, (b) PA, and (c) aniline on $\mathrm{MnO}_{2}$ in different time interval over a wide range of $\mathrm{pH}$ from 4.0 to 9.0.

with reaction time. This provided supporting evidence for the new product of azophenylarsonic acid, observed over a wide $\mathrm{pH}$ range (Fig. 4 and Fig. S6), which was confirmed by UPLC-Q-TOF-MS results, while benzoquinone was found at $\mathrm{pH} 4.0$ (Fig. 4c). At pH 6.0 after adsorption of $p$-ASA on $\mathrm{MnO}_{2}$, there was a decrease in absorbance; however, no shift of the absorbance band was observed as the reaction time increased; whereas, at $\mathrm{pH} 7.5$ and 9.0, there was a slight decrease in absorbance compared to that at $\mathrm{pH}$ 4.0 and 6.0. The adsorption kinetics results were also consistent with the rate of adsorption $\left(q_{\max }\right)$ being at a maximum at $\mathrm{pH} 4.0$ compared to that at 6.0, 7.5, and 9.0. Adsorption of $\mathrm{PA}$ on $\mathrm{MnO}_{2}$ at different $\mathrm{pH}$ resulted in a broad absorbance peak at $380 \mathrm{~nm}$ $(<500 \mathrm{~nm})$, which was observed to be more intense at $\mathrm{pH} 7.5$ and 9.0 than at 6.0 and 4.0, as evidenced by Fig. S5b. This might be explained by the appearance of the characteristic colloidal manganese oxides $\left(\mathrm{MnO}_{2}\right)$ (Butterfield et al., 2013), leading to elevated release of $\mathrm{Mn}$ concentration with increased pH (Jiang et al., 2010; Perez-Benito, 2003; Sun et al., 2015). However, the PA spectra did not vary significantly over a wide range of $\mathrm{pH}$.

A similar UV spectrum trend was observed in the case of aniline, where the UV-visible spectrum showed changes after adsorption of aniline on $\mathrm{MnO}_{2}$ over a wide range of $\mathrm{pH}$ (Fig. 3i, j, k, and l). At pH 4.0 , a peak that appeared at $245 \mathrm{~nm}$ assigned to benzoquinone was also observed in the aniline spectrum (Fig. S5c) (Kumar and Mathur, 2006; Laha and Luthy, 1990). Furthermore, a new broad peak appeared between $300 \mathrm{~nm}$ and $480 \mathrm{~nm}$, indicating the formation of the new product azobenzene (Jiang et al., 2016; Karunakaran et al.,
2005; Laha and Luthy, 1990). The formation of the new absorbance band demonstrated the oxidation of aniline and the formation of an intermediate, dependent on the reaction time (Ma et al., 2008). A decrease in absorbance was observed at $230 \mathrm{~nm}$ in all three $\mathrm{pH}$ conditions viz. 6.0, 7.5, and 9.0. The pattern of decreasing absorbance was similar to the behavior of the $q_{\max }$ value of aniline, which depends upon the adsorption of aniline on $\mathrm{MnO}_{2}$ at different $\mathrm{pH}$. A new weak absorbance band at (300 nm-480 nm) was also observed, and the absorbance intensity decreased with increasing $\mathrm{pH}$, which indicated a slight formation of a new product at $\mathrm{pH} 6.0$ and 7.5.

Characterization of the oxidation intermediates of $p$-ASA on $\mathrm{MnO}_{2}$ over a wide range of $\mathrm{pH}$ was carried out via UPLC-ICP-MS (Fig. 5a, b, c, and d). Identification of arsenic species was confirmed based on the retention time of standard solutions of $\mathrm{As}(\mathrm{III})(300 \mathrm{~s}), \mathrm{As}(\mathrm{V})(800 \mathrm{~s})$, and p-ASA (1100 s), respectively. p-ASA was converted into As(III), then it was further rapidly oxidized into As(V) (Manning et al., 2002; Zhu et al., 2014). The complete conversion of $p$-ASA into $\mathrm{As}(\mathrm{V})$ indicated that the adsorbed $p$-ASA could be oxidized to $\mathrm{As}(\mathrm{V})$ by $\mathrm{MnO}_{2}$ within $3.0 \mathrm{~h}$ (Fig. 5a). The release of a low concentration of $\mathrm{As}(\mathrm{V})$ at $\mathrm{pH} 6.0$ (Fig. 5b) and $\mathrm{As}(\mathrm{III})$ and $\mathrm{As}(\mathrm{V})$ at $\mathrm{pH} 7.5$ (Fig. 5c and Fig. S7) was observed, suggesting slow oxidation of $p$-ASA on $\mathrm{MnO}_{2}$, respectively. However, the oxidative and adsorptive rate was too low to observe at $\mathrm{pH} 9.0$ (Fig. 5d).

To support our hypotheses, complementary experiments using HPLC were further conducted to determine the adsorptive and oxidative behavior of $p$-ASA on $\mathrm{MnO}_{2}$, which confirmed the complete oxidation of $p$-ASA at $\mathrm{pH}$ 4.0. However, the oxidation of $p$-ASA at $\mathrm{pH} 6.0,7.5$, and 9.0 did not change appreciably (Fig. S8). When the degradation or transformation of aniline after adsorption on $\mathrm{MnO}_{2}$ was investigated using HPLC, two new peaks were observed at $\mathrm{pH} 4.0$, indicating the formation of new products (Fig. 5e). The combined results of UV-vis spectra and HPLC confirmed that the intermediate products were azobenzene and benzoquinone (Laha and Luthy, 1990).

\subsection{Adsorption and oxidation mechanism}

In order to uncover the adsorption mechanism, characterization of $\mathrm{MnO}_{2}$ surface was also carried out. A band at $518 \mathrm{~cm}^{-1}$ in the FTIR spectrum could be assigned to the $\mathrm{Mn}-\mathrm{O}$ stretching vibrations of $\mathrm{MnO}_{2}$ (Fig. 6a) (Chen et al., 2011). A peak at $1630 \mathrm{~cm}^{-1}$ was attributed to the deformation vibration of water molecules, indicating the presence of water adsorbed on the adsorbent surface (Fig. 6a) (Zhang et al., 2007). The peaks at $1590 \mathrm{~cm}^{-1}$ and $1510 \mathrm{~cm}^{-1}$ were attributed to $\mathrm{N}=\mathrm{Q}=\mathrm{N}$ stretching in the quinone ring and the $\mathrm{C}=\mathrm{C}$ stretching vibration of benzenoid rings, respectively (Fig. $6 \mathrm{~b}$, e), (Chen et al., 2011; Zujovic et al., 2008) resulting from the aromatic amine group in $p$-ASA and aniline moiety. The peaks at $1385 \mathrm{~cm}^{-1}$ and $1309 \mathrm{~cm}^{-1}$ were attributed to the $\mathrm{N}=\mathrm{N}$ and $\mathrm{C}-\mathrm{N}$ stretching vibrations in the vicinity of a quinonoid ring (Fig. 6b) (Anunziata et al., 2008; Buffeteau et al., 1998; Kang et al., 1998; Wang et al., 2008). Peaks at $1151 \mathrm{~cm}^{-1}$ and $1140 \mathrm{~cm}^{-1}$ might be assigned to the vibration modes of radical intermediates of aniline and $p$-ASA, which might have been formed during the protonation step (Fig. 6b, e) (Trchová et al., 2005). Additionally, the unshared electron pair on the $\mathrm{NH}_{2}$ group supported the oxidative coupling reaction of the benzene ring (Anunziata et al., 2008). The peak at $828 \mathrm{~cm}^{-1}$ could be ascribed to the out-of-plane vibration of the 1,4disubstituted benzene ring (Fig. 6b) (Wang et al., 2008). The presence of peaks at $1590,1510,1385$, and $1309 \mathrm{~cm}^{-1}$ is a common characteristic of the oxidation products of aniline and $p$-ASA (Stejskal et al., 2008). Due to the lower adsorption efficiency, negligible changes were observed after PA adsorption (Fig. 6c, d). 


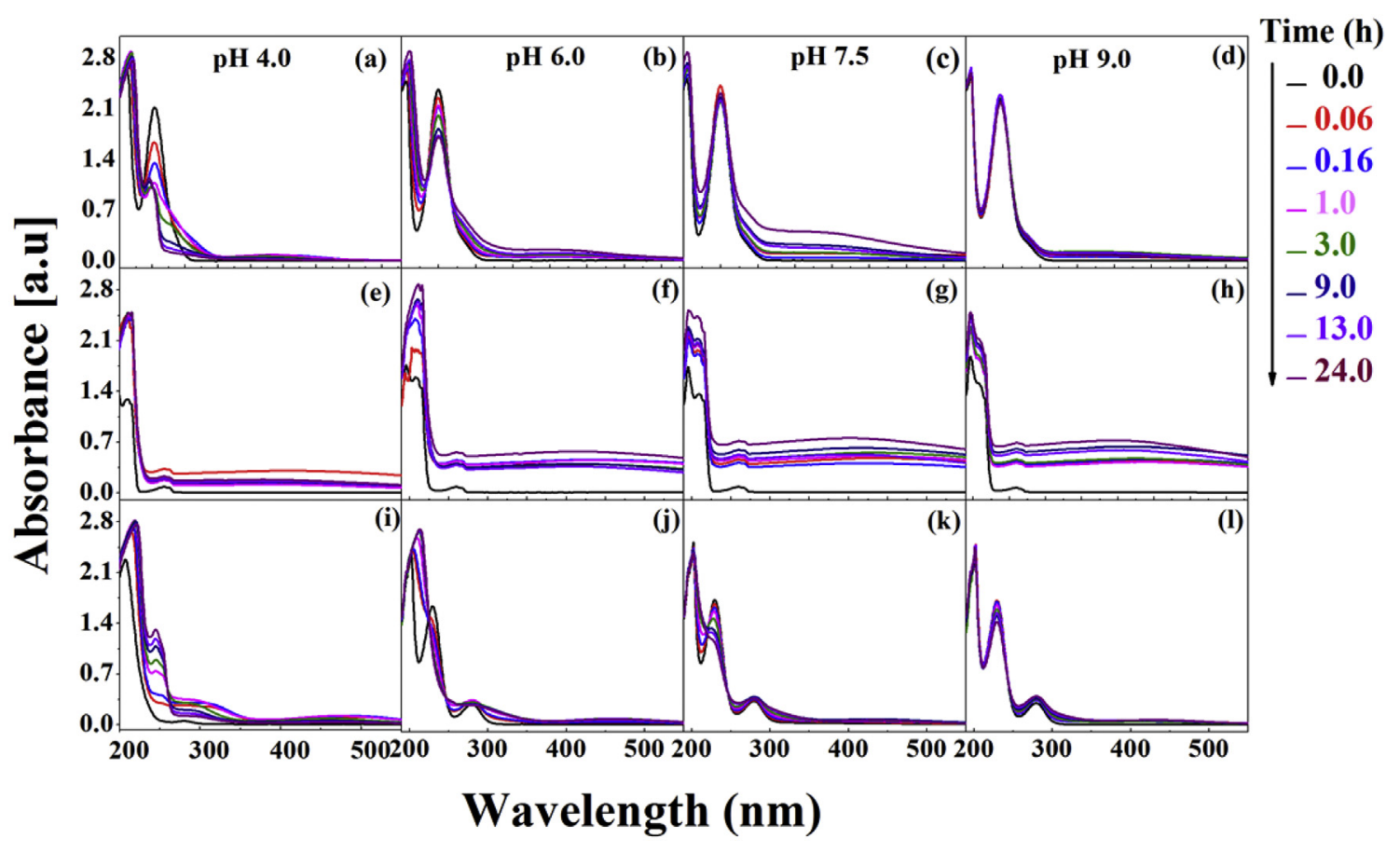

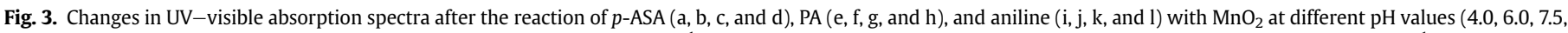

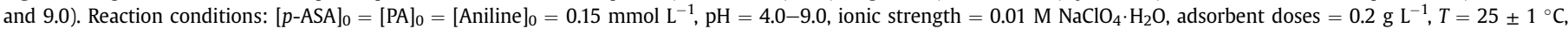
$t=24.0 \mathrm{~h}$.

However, Fig. 6e, f clearly show that after adsorption of $p$-ASA onto $\mathrm{MnO}_{2}$, the peak at $843 \mathrm{~cm}^{-1}$ attributed to the As-O stretching vibration of $p$-ASA shifts to $846 \mathrm{~cm}^{-1}$ (Zhang et al., 2007). Moreover, lowering of symmetry was observed after adsorption of $p$-ASA on $\mathrm{MnO}_{2}$, and the shifted band indicated the formation of inner sphere complexes (Goldberg and Johnston, 2001). Overall, we confirmed
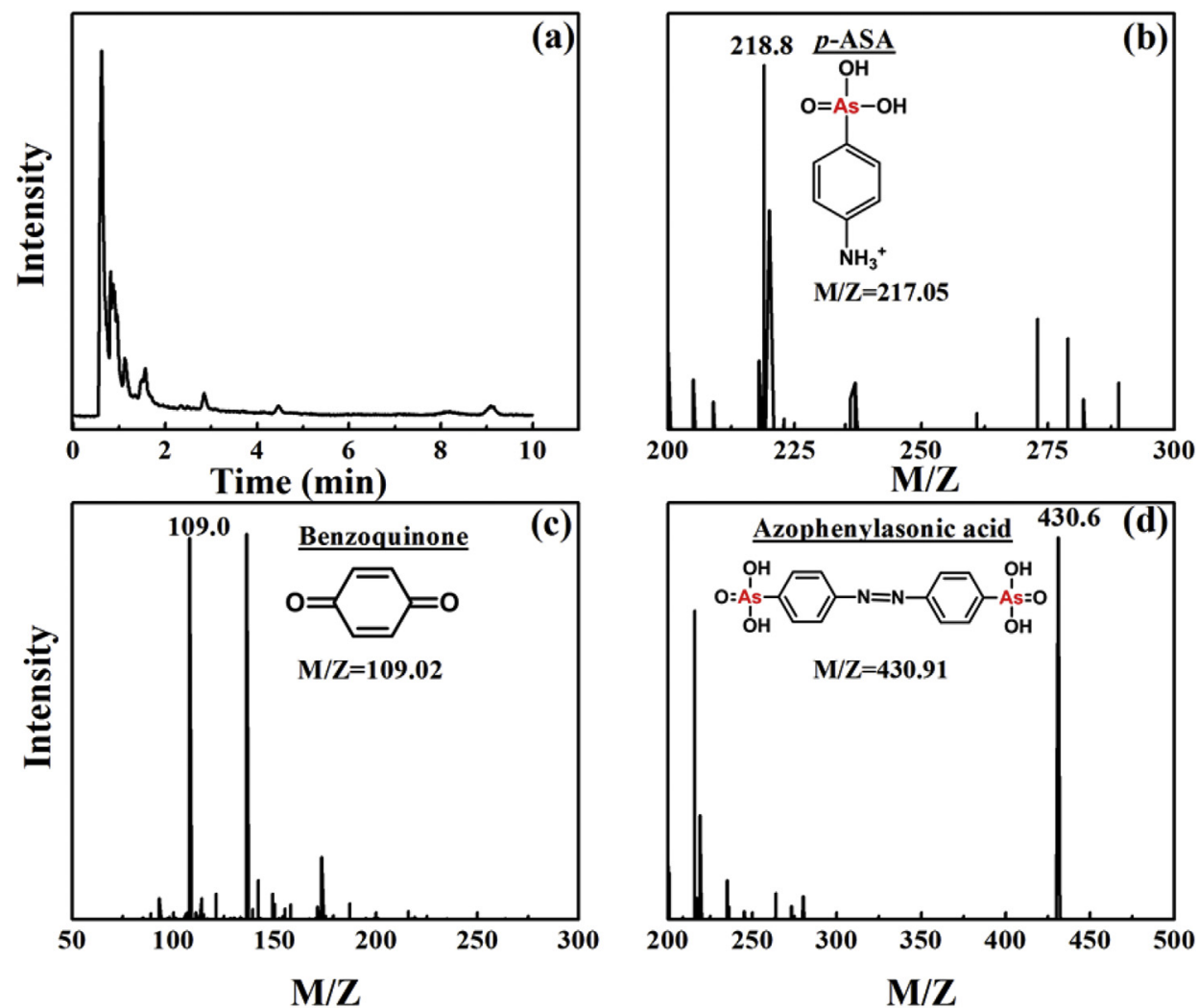

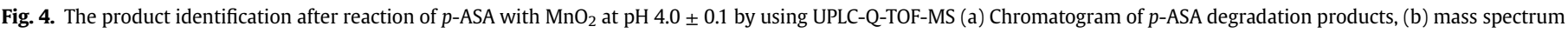
of $p$-ASA, (c) benzoquinone, and (d) azophenylarsonic acid. 

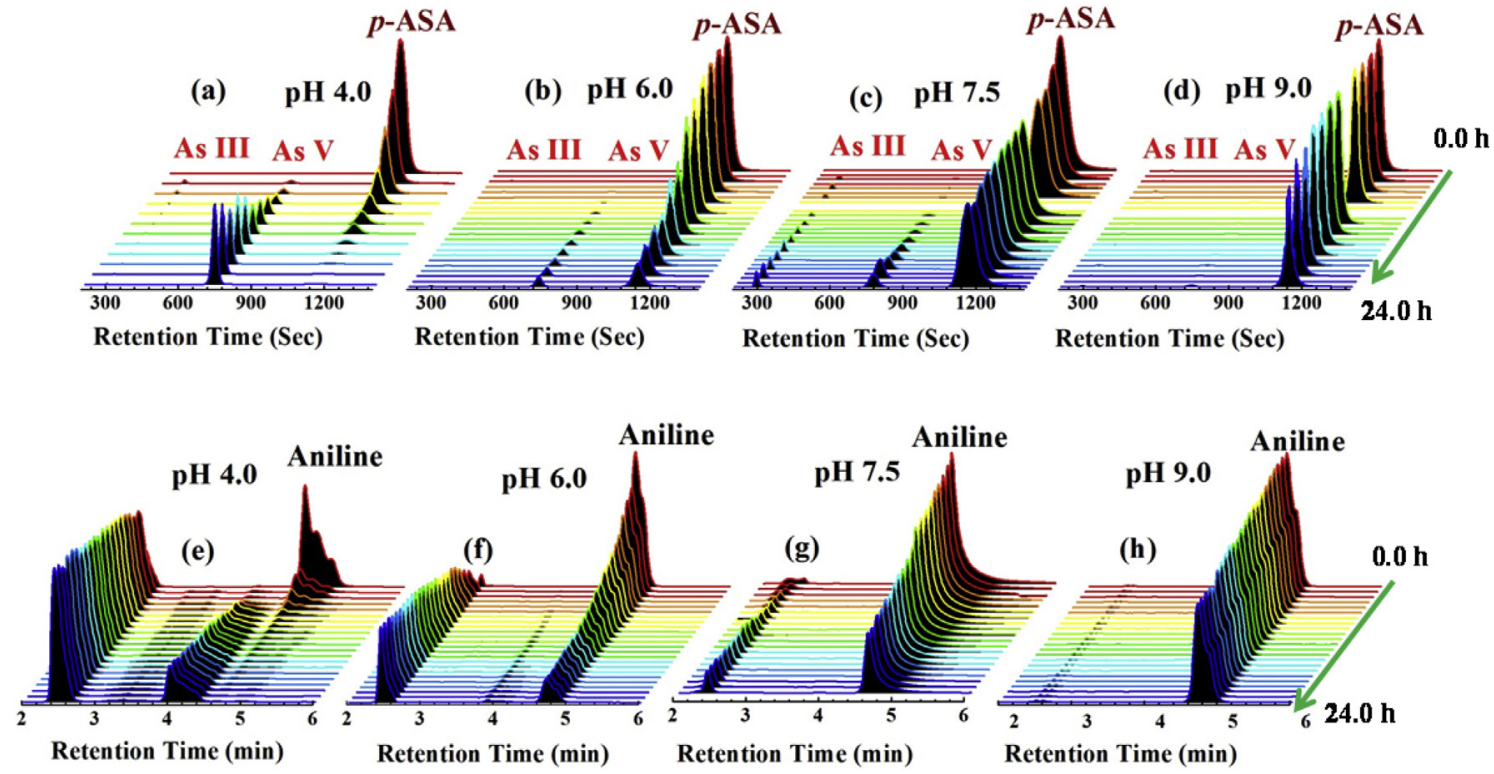


$[p-A S A]_{0}=[\mathrm{PA}]_{0}=[\text { Aniline }]_{0}=0.15 \mathrm{mmol} \mathrm{L}{ }^{-1}, \mathrm{pH}=4.0-9.0$, ionic strength $=0.01 \mathrm{M} \mathrm{NaClO}_{4} \cdot \mathrm{H}_{2} \mathrm{O}$, adsorbent doses $=0.2 \mathrm{~g} \mathrm{~L}{ }^{-1}, T=25 \pm 1{ }^{\circ} \mathrm{C}, t=24.0 \mathrm{~h}$.

that the amine group present in $p$-ASA and the aniline moiety influenced the adsorption and oxidation process.

Furthermore, the chemical state of Nitrogen $(\mathrm{N})$ was further investigated by XPS analysis after the adsorption of $p$-ASA and aniline on $\mathrm{MnO}_{2}$. The high resolution N 1s XPS spectra could be deconvoluted into two different components (Fig. 7a, b). The peaks at $400.4 \mathrm{eV}$ in $p$-ASA and $400.0 \mathrm{eV}$ in aniline after adsorption on $\mathrm{MnO}_{2}$ were assigned to the quinoid amine $\left(\mathrm{NH}^{+}\right)$and nitrogen cationic radical $\left(\mathrm{N}^{+}\right.$) (Han et al., 2014). Additionally, XPS fitted spectra of $\mathrm{N} 1 \mathrm{~s}$ showed another peak at $399.0 \mathrm{eV}$ related to nitrogen of the azo-functionality group for $p$-ASA and aniline after

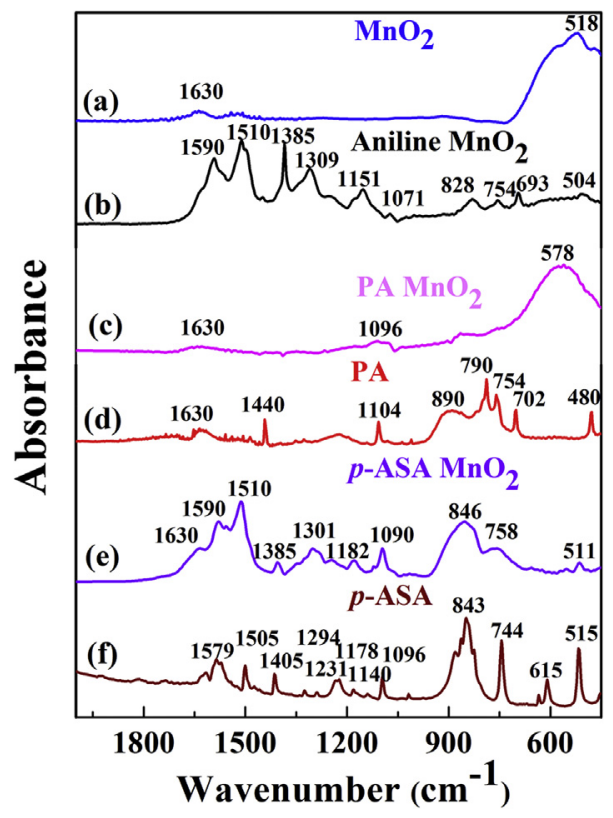

Fig. 6. Fourier transform infrared (FTIR) spectra of (a) $\mathrm{MnO}_{2}$, (b) aniline with $\mathrm{MnO}_{2}$, (c) $\mathrm{PA}$ with $\mathrm{MnO}_{2}$, (d) $\mathrm{PA}$, (e) $p$-ASA with $\mathrm{MnO}_{2}$, and (f) $p$-ASA at $\mathrm{pH} 4.0 \pm 0.1$. Experimental condition: $[p-\mathrm{ASA}]_{0}=[\mathrm{PA}]_{0}=[\text { Aniline }]_{0}=7.5 \mathrm{mmol} \mathrm{L} \mathrm{L}^{-1}, \mathrm{pH}=4.0$, ionic strength $=0.01 \mathrm{M} \mathrm{NaClO}_{4} \cdot \mathrm{H}_{2} \mathrm{O}$, adsorbent doses $=0.2 \mathrm{~g} \mathrm{~L}^{-1}, T=25 \pm 1{ }^{\circ} \mathrm{C}, t=24.0 \mathrm{~h}$. adsorption (Elbing et al., 2008), which was supported by the above experiments involving UV spectra of $p$-ASA and aniline after reaction with $\mathrm{MnO}_{2}$, as well as UPLC-Q-TOF-MS and FTIR.

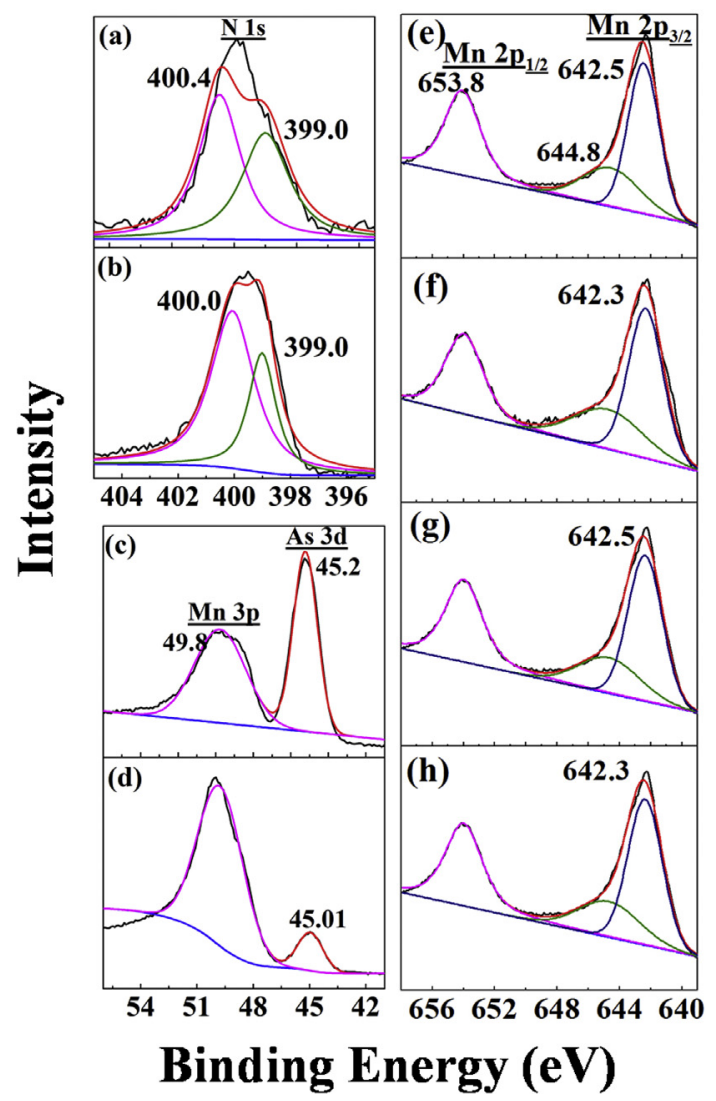

Fig. 7. X-ray photoelectron spectroscopy (XPS) core level spectra of $\mathrm{N} 1 \mathrm{~s}$ adsorption of (a) p-ASA and (b) aniline, As 3d spectra after adsorption of (c) p-ASA and (d) PA, and $\mathrm{Mn} 2 \mathrm{p}$ (e) $\mathrm{MnO}_{2}$, after adsorption of (f) $\mathrm{p}$-ASA, (g) $\mathrm{PA}$, and (h) aniline onto $\mathrm{MnO}_{2}$. Experimental condition: $[p-A S A]_{0}=[\mathrm{PA}]_{0}=[\text { Aniline }]_{0}=7.5 \mathrm{mmol} \mathrm{L}^{-1}, \mathrm{pH}=4.0$, ionic strength $=0.01 \mathrm{M} \mathrm{NaClO}_{4} \cdot \mathrm{H}_{2} \mathrm{O}$, adsorbent doses $=0.2 \mathrm{~g} \mathrm{~L}^{-1}, T=25 \pm 1^{\circ} \mathrm{C}, t=24.0 \mathrm{~h}$. 
Table 1

Elemental compositions of $\mathrm{MnO}_{2}, p$-ASA with $\mathrm{MnO}_{2}, \mathrm{PA}$ with $\mathrm{MnO}_{2}$, aniline with $\mathrm{MnO}_{2}, p$-ASA, and PA.

\begin{tabular}{llllll}
\hline S.N & Sample & $\mathrm{Mn}(\mathrm{t})$ at.\% & As $(\mathrm{t})$ at.\% & $\mathrm{N}(\mathrm{t})$ at.\% & $\mathrm{O}(\mathrm{t})$ at.\% \\
\hline 1 & $\mathrm{MnO}_{2}$ & 21.86 & - & 1.04 & 43.43 \\
2 & $p$-ASA with $\mathrm{MnO}_{2}$ & 8.70 & 4.75 & 5.52 & 28.66 \\
3 & ${\mathrm{PA} \mathrm{with} \mathrm{MnO}_{2}}$ & 21.70 & 1.06 & 0.89 & 41.05 \\
4 & Aniline with $\mathrm{MnO}_{2}$ & 9.49 & - & 7.37 & 23.02 \\
5 & $p$-ASA & - & 9.33 & 10.27 & 19.51 \\
6 & PA & - & 11.35 & 0.41 & 19.83 \\
\hline
\end{tabular}

In addition, the full-scan spectrum and elemental composition revealed that $p$-ASA, PA, and aniline reacted with $\mathrm{MnO}_{2}$ (Fig. S9). The elemental distribution of the samples was also calculated by XPS results, which showed that total $\mathrm{Mn}(\mathrm{t})$ and $\mathrm{O}(\mathrm{t})$ was decreased in $p$-ASA and aniline after adsorption onto $\mathrm{MnO}_{2}$ (Nesbitt et al., 1998). In contrast, $\mathrm{Mn}(\mathrm{t})$ and $\mathrm{O}(\mathrm{t})$ content was not significantly decreased in PA. Furthermore, total arsenic was higher in $p$-ASA than PA and total nitrogen was higher in aniline than $p$-ASA is given in Table 1. As 3d XPS spectrum showed binding energies of 45.2 and $45.0 \mathrm{eV}$ (Fig. 7c, d), which corresponded to As(V) (Ouvrard et al., 2005; Wei et al., 2011). After the reaction of $p$-ASA and PA with $\mathrm{MnO}_{2}$, an additional peak appeared at binding energy $49.8 \mathrm{eV}$, which is attributed to Mn 3p core levels (Ouvrard et al., 2005). This new Mn 3p peak was higher for PA and lower for $p$-ASA, which showed that the oxidation and adsorption of $p$-ASA on $\mathrm{MnO}_{2}$ were higher than for PA (Fig. 7c, d). Peaks observed at $642.5 \mathrm{eV}$ and $653.8 \mathrm{eV}$ corresponded to $\mathrm{Mn} 2 \mathrm{p}_{3 / 2}$ and $\mathrm{Mn} 2 \mathrm{P}_{1 / 2}$ (Fig. 7e). The peak-to-peak separation value for $\mathrm{Mn} 2 \mathrm{P}_{1 / 2}$ and $\mathrm{Mn} \mathrm{2} \mathrm{p}_{3 / 2}$ was $11.3 \mathrm{eV}$, indicating the presence of $\mathrm{Mn}^{\mathrm{IV}}$ ions (Biesinger et al., 2011; Jiang et al., 2016), which was further confirmed by the fitting data for $\mathrm{MnO}_{2}$ at $644.8 \mathrm{eV}$ (He et al., 2014). After adsorption, lowered binding energies were observed for $p$-ASA and aniline, while no change was observed for PA, corresponding to the higher release of
Mn with p-ASA and aniline (Nesbitt et al., 1998). XPS results also confirmed that almost no significant change took place during adsorption and oxidation of PA on $\mathrm{MnO}_{2}$.

\subsection{Proposed removal mechanisms}

Thus, based on a combination of the identified intermediates in solution and the final products on the surface, a removal mechanism for $p$-ASA on $\mathrm{MnO}_{2}$ is proposed in Fig. 8. During the initial stage of the reaction, the main $p$-ASA removal mechanism was adsorption. The monodentate complex was formed on the surface of $\mathrm{Mn}(\mathrm{IV})$ by the removal of $\mathrm{H}^{+}$(Step I). As the reaction process continued, $p$-ASA oxidation capacity was significantly improved through the transfer of one electron from $p$-ASA on $\mathrm{MnO}_{2}$ surface $\left(\mathrm{Mn}^{\mathrm{IV}}\right)$ to produce a $\mathrm{p}$-ASA radical intermediate, followed by the reduction of $\mathrm{MnOOH}\left(\mathrm{Mn}^{\mathrm{III}}\right)$ to $\mathrm{Mn}^{\mathrm{II}}$ in the solution (Step I) (Wang and Cheng, 2015; Zhang and Huang, 2005). Additionally, the reductive dissolution of $\mathrm{Mn}(\mathrm{IV})$ oxide and re-adsorption of $\mathrm{Mn}^{\mathrm{II}}$ represented significantly (Liu et al., 2015). The radical intermediate could be further hydrolyzed to form a benzoquinone, indicating the effective coupling of the radical intermediate and the hydrolysis reaction, resulting in the formation of a new product (Step II). Similarly, the oxidation of $p$-ASA radical caused it to be cleaved to form arsenite (III), and then oxidized into arsenate (V) with the release of manganese $(\mathrm{Mn})$ in the solution, indicating a heterogeneous oxidation process. Moreover, $p$-ASA radical intermediate was again transformed through radical-to-radical coupling to form an azophenylarsonic acid, which was observed over the whole $\mathrm{pH}$ range, with the release of $\mathrm{Mn}$ through reductive dissolution, causing transfer of two electrons (Step III) (Gao et al., 2012; Laha and Luthy, 1990; Wang and Cheng, 2015; Zhang and Huang, 2005). Additionally, $\mathrm{Mn}$ (aq) release rate was proportional to the precursor complex formation during the adsorption process, and electron transfer could occur through inner-sphere, outer-sphere

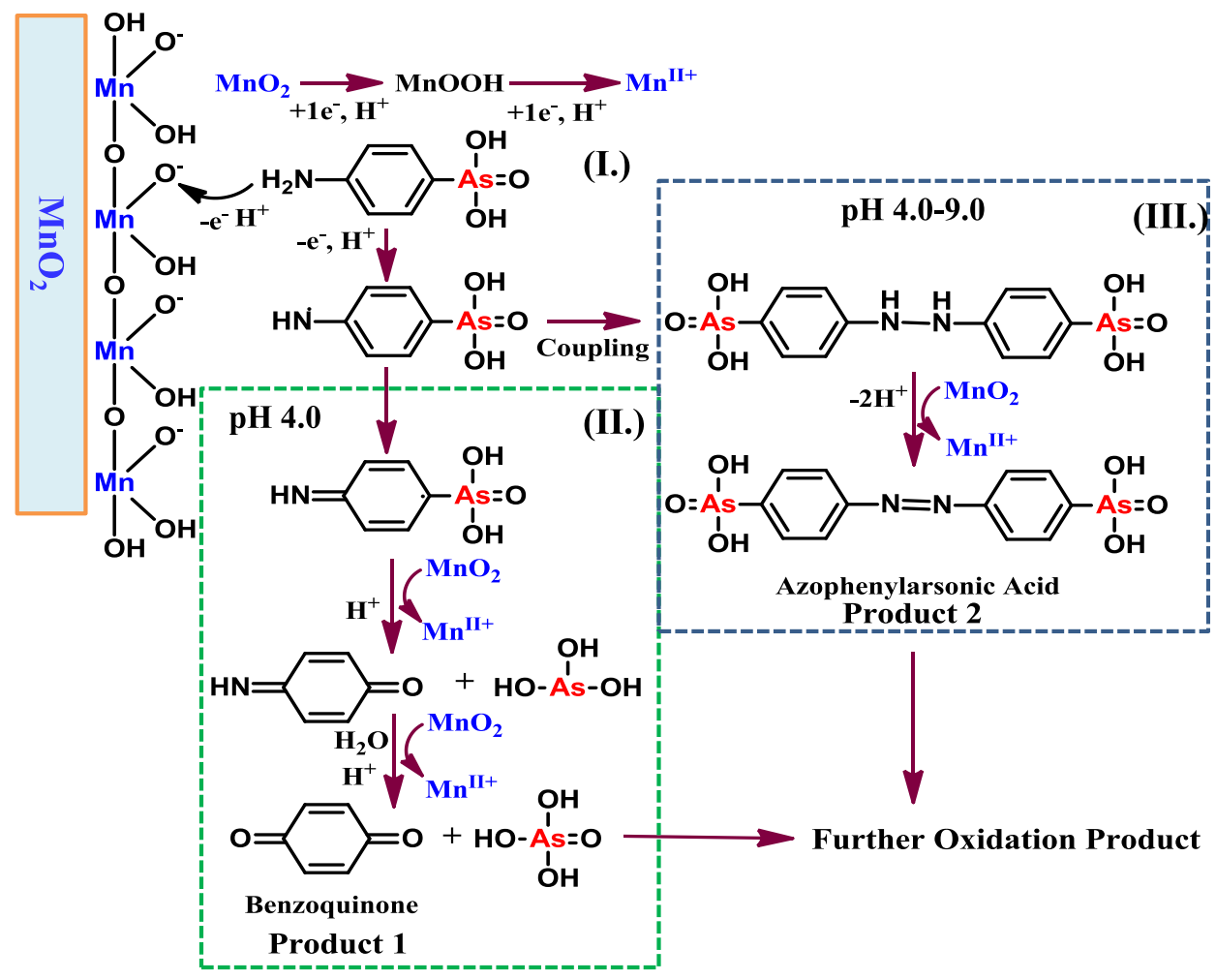

Fig. 8. Schematic diagram for the proposed adsorption and oxidation mechanism of $p-\mathrm{ASA}_{\text {on }} \mathrm{MnO}_{2}$ at $\mathrm{pH} 4.0 \pm 0.1$. 
precursor formation, depending on the reactants and other conditions (Wang and Cheng, 2015). Furthermore, after adsorption of aniline on $\mathrm{MnO}_{2}$ at $\mathrm{pH} 4$.0, oxidized products may be benzoquinone and azobenzene (Fig. S10a) (Laha and Luthy, 1990; Wang and Cheng, 2015), which would be further oxidized. Additionally, proposed reaction products of $\mathrm{PA}$ on $\mathrm{MnO}_{2}$ at $\mathrm{pH} 4.0$ are $\mathrm{As}(\mathrm{V})$ and phenol, which might be the possible degradation products (Fig. S10b) (Zheng et al., 2010).

\section{Conclusions}

We developed a removal process based on adsorption following oxidation of para arsanilic acids ( $p$-ASA) and suggested the transformation mechanism. To the best of our knowledge, this is the first report to demonstrate the adsorption mechanism for $p$-ASA in its structural level. This study provided significant contribution to control the environmental risk. The adsorption kinetics experiments revealed that removal rates of $p$-ASA, PA, and aniline by adsorption were strongly $\mathrm{pH}$ dependent. The oxidative and adsorptive properties of $p$-ASA, PA, and aniline onto $\mathrm{MnO}_{2}$, were examined thereby recognizing protonated amine as the major functional group affecting the transformation pathway. The results derived on the basis of changes in UV spectra and spectroscopic study gave a plausible explanation for the formation of the new oxidation products. Increased oxidation of $p$-ASA on $\mathrm{MnO}_{2}$ was observed with the major products including arsenate, benzoquinone, and azophenylarsonic acid. Identification of the products provided further insights into the oxidation of $p$-ASA on $\mathrm{MnO}_{2}$. Furthermore, in depth mechanistic studies are still needed to examine a detailed mechanistic understanding of organoarsenic transformation by $\mathrm{MnO}_{2}$.

\section{Acknowledgements}

This study was supported by the Natural Science Foundation of China (grant numbers 51422813, 51225805, 51378490).

\section{Appendix A. Supplementary data}

Supplementary data related to this article can be found at http:// dx.doi.org/10.1016/j.watres.2017.03.028.

\section{References}

Anunziata, O.A., Gómez Costa, M.B., Martínez, M.L., 2008. Interaction of water and aniline adsorbed onto Na-AIMCM-41 and Na-AISBA-15 catalysts as hosts materials. Catal. Today 133-135, 897-905.

Biesinger, M.C., Payne, B.P., Grosvenor, A.P., Lau, L.W.M., Gerson, A.R., Smart, R.S.C., 2011. Resolving surface chemical states in XPS analysis of first row transition metals, oxides and hydroxides: Cr, Mn, Fe, Co and Ni. Appl. Surf. Sci. 257 (7), $2717-2730$.

Buffeteau, T., Lagugné Labarthet, F., Pézolet, M., Sourisseau, C., 1998. Photoinduced orientation of azobenzene chromophores in amorphous polymers as studied by real-time visible and FTIR spectroscopies. Macromolecules 31 (21), 7312-7320.

Butterfield, C.N., Soldatova, A.V., Lee, S.W., Spiro, T.G., Tebo, B.M., 2013. Mn(II,III) oxidation and $\mathrm{MnO}_{2}$ mineralization by an expressed bacterial multi-copper oxidase. Proc. Natl. Acad. Sci. 110 (29), 11731-11735.

Chapman, H.D., Johnson, Z.B., 2002. Use of antibiotics and roxarsone in broiler chickens in the USA: analysis for the years 1995 to 2000. Poult. Sci. 81 (3), 356-364.

Chen, G., Zhao, L., Dong, Y.H., 2011. Oxidative degradation kinetics and products of chlortetracycline by manganese dioxide. J. Hazard. Mater. 193, 128-138.

Clarke, C.E., Kielar, F., Johnson, K.L., 2013. The oxidation of acid azo dye AY 36 by a manganese oxide containing mine waste. J. Hazard. Mater. 246-247, 310-318.

Cortinas, I., Field, J.A., Kopplin, M., Garbarino, J.R., Gandolfi, A.J., Sierra-Alvarez, R , 2006. Anaerobic biotransformation of roxarsone and related N-substituted phenylarsonic acids. Environ. Sci. Technol. 40 (9), 2951-2957.

Cui, H.J., Cai, J.K., Zhao, H., Yuan, B., Ai, C.L., Fu, M.L., 2014. Fabrication of magnetic porous Fe-Mn binary oxide nanowires with superior capability for removal of As(III) from water. J. Hazard. Mater. 279, 26-31.

Czaplicka, M., Bratek, Ł., Jaworek, K., Bonarski, J., Pawlak, S., 2014. Photo-oxidation of p-arsanilic acid in acidic solutions: kinetics and the identification of byproducts and reaction pathways. Chem. Eng. J. 243, 364-371.

Depalma, S., Cowen, S., Hoang, T., Al-Abadleh, H.A., 2008. Adsorption thermodynamics of p-arsanilic acid on iron (oxyhydr)oxides: in-situ ATR-FTIR studies. Environ. Sci. Technol. 42 (6), 1922-1927.

Elbing, M., Błaszczyk, A., von Hänisch, C., Mayor, M., Ferri, V., Grave, C., Rampi, M.A., Pace, G., Samorì, P., Shaporenko, A., Zharnikov, M., 2008. Single component selfassembled monolayers of aromatic azo-biphenyl: influence of the packing tightness on the SAM structure and light-induced molecular movements. Adv. Funct. Mater. 18 (19), 2972-2983.

Ewies, H.A.A.M.A.E.F., 2013. State of the art on chemistry and applications of organoarsenic compounds. Am. J. Res. Commun. 1 (12), 268-325.

Gao, J., Hedman, C., Liu, C., Guo, T., Pedersen, J.A., 2012. Transformation of sulfamethazine by manganese oxide in aqueous solution. Environ. Sci. Technol. 46 (5), 2642-2651.

Garbarino, J.R., Bednar, A.J., Rutherford, D.W., Beyer, R.S., Wershaw, R.L., 2003. Environmental fate of roxarsone in poultry litter. I. degradation of roxarsone during composting. Environ. Sci. Technol. 37 (8), 1509-1514.

Goldberg, S., Johnston, C.T., 2001. Mechanisms of arsenic adsorption on amorphous oxides evaluated using macroscopic measurements, vibrational spectroscopy, and surface complexation modeling. J. Colloid Interface Sci. 234 (1), 204-216.

Han, G., Liu, Y., Zhang, L., Kan, E., Zhang, S., Tang, J., Tang, W., 2014. $\mathrm{MnO}_{2}$ nanorods intercalating graphene oxide/polyaniline ternary composites for robust highperformance supercapacitors. Sci. Rep. 4, 1-7.

He, C., Shen, B., Chen, J., Cai, J., 2014. Adsorption and oxidation of elemental mercury over Ce-MnO $/$ Ti-PILCs. Environ. Sci. Technol. 48 (14), 7891-7898.

Ho, Y.S., Mckay, G., 1998. A comparison of chemisorption kinetic models applied to pollutant removal on various sorbents. Process Saf. Environ. Prot. 76 (B4), 332-340.

Huang, L., Yao, L., He, Z., Zhou, C., Li, G., Yang, B., Deng, X., 2014. Roxarsone and its metabolites in chicken manure significantly enhance the uptake of As species by vegetables. Chemosphere 100, 57-62.

Jiang, J., Pang, S.Y., Ma, J., 2010. Role of ligands in permanganate oxidation of organics. Environ. Sci. Technol. 44 (11), 4270-4275.

Jiang, L., Liu, L., Xiao, S., Chen, J., 2016. Preparation of a novel manganese oxidemodified diatomite and its aniline removal mechanism from solution. Chem. Eng. J. 284, 609-619.

Joshi, T.P., Zhang, G., Jefferson, W.A., Perfilev, A.V., Liu, R., Liu, H., Qu, J., 2017. Adsorption of aromatic organoarsenic compounds by ferric and manganese binary oxide and description of the associated mechanism. Chem. Eng. J. 309, 577-587.

Jung, B.K., Jun, J.W., Hasan, Z., Jhung, S.H., 2015. Adsorptive removal of p-arsanilic acid from water using mesoporous zeolitic imidazolate framework-8. Chem. Eng. J. 267, 9-15.

Kang, E.T., Neoh, K.G., Tan, K.L., 1998. Polyaniline: a polymer with many interesting intrinsic redox states. Prog. Polym. Sci. 23 (97), 277-324.

Karunakaran, C., Senthilvelan, S., Karuthapandian, S., 2005. $\mathrm{TiO}_{2}$ photocatalyzed oxidation of aniline. J. Photochem. Photobiol. A Chem. 172 (2), 207-213.

Klausen, J., Haderlein, S.B., Schwarzenbach, R.P., 1997. Oxidation of substituted anilines by aqueous $\mathrm{MnO}_{2}$ : effect of co-solutes on initial and quasi-steady-state kinetics. Environ. Sci. Technol. 31 (9), 2642-2649.

Kumar, A., Mathur, N., 2006. Photocatalytic degradation of aniline at the interface of $\mathrm{TiO}_{2}$ suspensions containing carbonate ions. J. Colloid Interface Sci. 300 (1), $244-252$.

Kunde, L., Weiping, L., Jay, G., 2009. Oxidative removal of bisphenol A by manganese dioxide: efficacy, products, and pathways. Environ. Sci. Technol. 43 (10), 3860-3864.

Lafferty, B.J., Matthew, G.V., Sparks, D.L., 2010. Arsenite oxidation by a poorly crystalline manganese-oxide 1. stirred-flow experiments. Environ. Sci. Technol. 44 (22), 8460-8466.

Lafferty, B.J., Matthew, G.V., Sparks, D.L., 2011. Arsenite oxidation by a poorlycrystalline manganese oxide. 3. arsenic and manganese desorption. Environ. Sci. Technol. 45 (21), 9218-9223.

Laha, S., Luthy, R.G., 1990. Oxidation of aniline and other primary aromatic-amines by manganese-dioxide. Environ. Sci. Technol. 24 (3), 363-373.

Li, H., Lee, L.S., Schulze, D.G., Guest, C.A., 2003. Role of soil manganese in the oxidation of aromatic amines. Environ. Sci. Technol. 37 (12), 2686-2693.

Liu, R., Xu, W., He, Z., Lan, H., Liu, H., Qu, J., Prasai, T., 2015. Adsorption of antimony $(\mathrm{V})$ onto $\mathrm{Mn}(\mathrm{II})$-enriched surfaces of manganese-oxide and FeMn binary oxide. Chemosphere 138, 616-624.

Ma, H., Zhu, Z., Wang, B., 2008. Simple synthesis of N-methyl aniline over modified kaolin for octane number improvement. Energy Fuels 22 (4), 2157-2159.

Mangalgiri, K.P., Adak, A., Blaney, L., 2015. Organoarsenicals in poultry litter: detection, fate, and toxicity. Environ. Int. 75, 68-80.

Manning, B.A., Fendorf, S.E., Bostick, B., Suarez, D.L., 2002. Arsenic (III) oxidation and arsenic(V) adsorption reactions on synthetic birnessite. Environ. Sci. Technol. 36 (5), 976-981.

Mclintock, I.S., 1967. The Elovich equation in chemisorption kinetics. Nature 216 (5121), 1204-1205.

Mitchell, W., Goldberg, S., Al-Abadleh, H.A., 2011. In situ ATR-FTIR and surface complexation modeling studies on the adsorption of dimethylarsinic acid and p-arsanilic acid on iron-(oxyhydr)oxides. J. Colloid Interface Sci. 358 (2), 534-540.

Morrison, J.L., 1969. Distribution of arsenic from poultry litter in broiler chickens, soil, and crops. J. Agric. Food Chem. 17 (6), 1288-1290. 
Nesbitt, H.W., Canning, G.W., Bancroft, G.M., 1998. XPS study of reductive dissolution of 703-birnessite by $\mathrm{H}_{3} \mathrm{AsO}_{3}$, with constraints on reaction mechanism. Geochim. Cosmochim. Acta 62 (12), 2097-2110.

Ouvrard, S., de Donato, P., Simonnot, M.O., Begin, S., Ghanbaja, J., Alnot, M., Duval, Y.B., Lhote, F., Barres, O., Sardin, M., 2005. Natural manganese oxide: combined analytical approach for solid characterization and arsenic retention. Geochim. Cosmochim. Acta 69 (11), 2715-2724.

Perez-Benito, J.F., 2003. Coagulation of colloidal manganese dioxide by divalent cations. Colloids Surf. A Physicochem. Eng. Asp. 225 (s 1-3), 145-152.

Rutherford, D.W., Bednar, A.J., Garbarino, J.R., Needham, R., Staver, K.W. Wershaw, R.L., 2003. Environmental fate of roxarsone in poultry litter. part II. mobility of arsenic in soils amended with poultry litter. Environ. Sci. Technol. 37 (8), 1515-1520

Stejskal, J., Sapurina, I., Trchová, M., Konyushenko, E.N., 2008. Oxidation of aniline: polyaniline granules, nanotubes, and oligoaniline microsphere. Macromolecules 41 (10), 3530-3536.

Stolz, J.F., Perera, E., Kilonzo, B., Kail, B., Crable, B., Fisher, E., Ranganathan, M., Wormer, L., Basu, P., 2007. Biotransformation of 3-Nitro-4-hydroxybenzene arsonic acid (roxarsone) and release of inorganic arsenic by Clostridium species. Environ. Sci. Technol. 41 (3), 818-823.

Stone, A.T., 1987. Reductive dissolution of manganese (III/IV) oxides by substituted phenols. Environ. Sci. Technol. 21 (10), 979-988.

Sun, B., Guan, X., Fang, J., Tratnyek, P.G., 2015. Activation of manganese oxidants with bisulfite for enhanced oxidation of organic contaminants: the involvement of Mn(III). Environ. Sci. Technol. 49 (20), 12414-12421.

Trchová, M., Šeděnková, I., Stejskal, J., 2005. In-situ polymerized polyaniline films 6. FTIR spectroscopic study of aniline polymerisation. Synth. Met. 154 (1-3), 1-4.

Wang, L., Cheng, H., 2015. Birnessite (delta- $\mathrm{MnO}_{2}$ ) mediated degradation of organoarsenic feed additive p-arsanilic acid. Environ. Sci. Technol. 49 (6), 3473-3481.

Wang, J., Wang, J., Yang, Z., Wang, Z., Zhang, F., Wang, S., 2008. A novel strategy for the synthesis of polyaniline nanostructures with controlled morphology. React. Funct. Polym. 68 (10), 1435-1440.

Weber, E.J., Spidle, D.L., Thorn, K.A., 1996. Covalent binding of aniline to humic substances. 1. kinetic studies. Environ. Sci. Technol. 30 (9), 2755-2763.

Wei, Y.T., Zheng, Y.M., Chen, J.P., 2011. Uptake of methylated arsenic by a polymeric adsorbent: process performance and adsorption chemistry. Water Res. 45 (6), $2290-2296$.

Xie, X., Hu, Y., Cheng, H., 2016a. Mechanism, kinetics, and pathways of selfsensitized sunlight photodegradation of phenylarsonic compounds. Water Res. 96, 136-147.

Xie, X., Hu, Y., Cheng, H., 2016b. Rapid degradation of p-arsanilic acid with simultaneous arsenic removal from aqueous solution using Fenton process. Water Res. 89, 59-67.

Zhang, H., Huang, C.H., 2003. Oxidative transformation of triclosan and chlorophene by manganese oxides. Environ. Sci. Technol. 37 (11), 2421-2430.

Zhang, H. Huang, C.H., 2005. Oxidative transformation of fluoroquinolone antibacterial agents and structurally related amines by manganese oxide. Environ. Sci. Technol. 39 (12), 4474-4483.

Zhang, G.S., Qu, J.H., Liu, H.J., Liu, R.P., Li, G.T., 2007. Removal mechanism of As(III) by a novel $\mathrm{Fe}-\mathrm{Mn}$ binary oxide adsorbent: oxidation and sorption. Environ. Sci. Technol. 41 (13), 4613-4619.

Zhang, G., Sun, M., Liu, Y., Lang, X., Liu, L., Liu, H., Qu, J., Li, J., 2015. Visible-light induced photocatalytic activity of electrospun- $\mathrm{TiO}_{2}$ in arsenic (III) oxidation. ACS Appl. Mater. Interfaces 7 (1), 511-518.

Zheng, S., Cai, Y., O'Shea, K.E., 2010. $\mathrm{TiO}_{2}$ photocatalytic degradation of phenylarsonic acid. J. Photochem. Photobiol. A Chem. 210 (1), 61-68.

Zhu, X.D., Wang, Y.J., Liu, C., Qin, W.X., Zhou, D.M., 2014. Kinetics, intermediates and acute toxicity of arsanilic acid photolysis. Chemosphere 107, 274-281.

Zujovic, Z.D., Zhang, L., Bowmaker, G.A., Kilmartin, P.A., Travas-Sejdic, J., 2008. Selfassembled, nanostructured aniline oxidation products: a structural investigation. Macromolecules 41 (9), 3125-3135. 